\title{
Influence of tillage methods and nurturing chemical on weed infestation and yield of pea (Pisum sativum L.) cultivar Merlin
}

\section{Wpływ metod uprawy roli i pielęgnacji chemicznej na zachwaszczenie i plonowanie grochu siewnego (Pisum sativum L.) odmiany Merlin}

\author{
Marek Gugała, Krystyna Zarzecka, Anna Sikorska
}

\section{Summary}

The aim of the studies carried out in the years 2008-2010 was to determine the effect of tillage methods (traditional and simplified) and nurturing chemical (using herbicides and mixtures of herbicides; Command $480 \mathrm{EC}-0.25 \mathrm{I} / \mathrm{ha}$, Butoxone M $400 \mathrm{SL}-$ $3.0 \mathrm{l} / \mathrm{ha}$, Fusilade Forte $150 \mathrm{EC}-1.5 \mathrm{l} / \mathrm{ha}$ ) on weed infestation and yield of pea cultivar Merlin. Used in the experiment method of tillage and herbicides, and their mixtures had a positive effect and decreased air-dry weight of weeds and at the same time increased the yield and weight of a thousand seeds of pea.

Key words: tillage methods; weed control methods; infestation; seeds yield

\section{Streszczenie}

Celem przeprowadzonych w latach 2008-2010 badań było określenie wpływu metod uprawy roli (tradycyjnej i uproszczonej) oraz pielęgnacji chemicznej (z użyciem herbicydów i ich mieszanin; Command 480 EC - 0,25 I/ha, Butoxone M 400 SL - 3,0 I/ha, Fusilade Forte $150 \mathrm{EC}-1,5 \mathrm{l} / \mathrm{ha}$ ) na zachwaszczenie i plonowanie grochu siewnego odmiany Merlin. Stosowane w doświadczeniu metody uprawy roli oraz herbicydy i ich mieszaniny korzystnie wpłynęły na obniżenie powietrznie suchej masy chwastów jednocześnie powodując wzrost plonu i masy tysiąca nasion grochu siewnego.

Słowa kluczowe: metody uprawy roli; sposoby pielęgnacji; zachwaszczenie; plon nasion

\footnotetext{
Uniwersytet Przyrodniczo-Humanistyczny w Siedlcach

Katedra Szczegółowej Uprawy Roślin

Prusa 14, 08-110 Siedlce

gugala@uph.edu.p
} 


\section{Wstęp / Introduction}

W ostatnich latach trwa dyskusja na temat odnowy produkcji roślin strączkowych, w której zwolennicy wskazują, że należy ją rozwijać, ze względu na pozytywne oddziaływanie tych roślin na środowisko oraz możliwość ich wykorzystania jako dodatkowego źródła białka w produkcji pasz. Oponenci natomiast wskazują wady produkcji tych roślin, wśród których wymienia się dużą wrażliwość na niekorzystne warunki pogodowe oraz niestabilność plonowania (Florek i wsp. 2012).

Potencjał plonowania grochu, który w naszym kraju jest wykorzystywany zaledwie w 50\%, można poprawić przez dobór odmian, właściwą uprawę, optymalny termin siewu, a także ukierunkowaną ochronę roślin, między innymi przed chwastami, gdyż mechaniczna pielęgnacja, zwłaszcza przy większej ilości opadów atmosferycznych nie zawsze daje zadawalające rezultaty. $\mathrm{Z}$ tego względu użycie odpowiednich herbicydów daje większą gwarancję utrzymania plantacji w stanie wolnym od chwastów (Szwejkowska 2006; Księżak 2007).

Innym ważnym czynnikiem wpływającym na wielkość plonu i jakość nasion może być dobór systemu uprawy roli. Tradycyjny system płużny jest najbardziej rozpowszechniony, ale kosztowny, dlatego w praktyce można go zastąpić mniej kosztochłonnymi, a więc uprawą uproszczoną lub zerową (Faligowska i Szukała 2011).

W ostatnich latach asortyment herbicydów zalecanych do stosowania $w$ grochu siewnym został mocno ograniczony, dlatego celem podjętych badań było określenie wpływu metod uprawy roli oraz sposobów pielęgnacji chemicznej na zachwaszczenie i plonowanie grochu siewnego odmiany Merlin.

\section{Materiały i metody / Materials and methods}

Doświadczenie polowe przeprowadzono w 2008-2010 roku w Rolniczej Stacji Doświadczalnej Zawady należącej do Uniwersytetu Przyrodniczo-Humanistycznego w Siedlcach. Doświadczenie założono jako dwuczynnikowe w układzie split-plot w trzech powtórzeniach. Badanymi czynnikami były:

I - dwie metody uprawy roli:

1. uprawa tradycyjna (bezpośrednio po zbiorze przedplonu zastosowano agregat podorywkowy na głębokość $10 \mathrm{~cm}$, następnie dwukrotnie w odstępach dwu- trzytygodniowych kultywatorowanie połączone $\mathrm{z}$ bronowaniem, trzecia dekada października orka przedzimowa głębokość $25 \mathrm{~cm}$, wiosną włókowanie, tuż przed siewem agregat uprawowy głębokość $10 \mathrm{~cm}$ ),

2. uprawa uproszczona (dwa tygodnie po zbiorze przedplonu zastosowano agregat podorywkowy na głębokość $15 \mathrm{~cm}$, pierwsza dekada października agregat podorywkowy głębokość $20 \mathrm{~cm}$, wiosną tuż przed siewem agregat uprawowy głębokość $15 \mathrm{~cm}$ ).

II - cztery sposoby pielęgnacji chemicznej:

1. obiekt kontrolny - pielęgnacja mechaniczna (od siewu do wschodów 1-krotne bronowanie, po wschodach 2-krotne bronowanie do osiągnięcia przez rośliny fazy 3 liści),
2. bezpośrednio po siewie opryskiwanie herbicydem Command 480 EC (chlomazon) w dawce 0,25 1/ha,

3. po wschodach w fazie 3 wąsów czepnych opryskiwanie herbicydem Butoxone M 400 SL (MCPB) w dawce 3,0 1/ha,

4. bezpośrednio po siewie opryskiwanie herbicydem Command 480 EC (chlomazon) w dawce 0,25 1/ha, po wschodach w fazie 3 wąsów czepnych opryskiwanie herbicydem Butoxone M 400 SL (MCPB) w dawce 3,0 1/ha,

5. bezpośrednio po siewie opryskiwanie herbicydem Command 480 EC (chlomazon) w dawce 0,25 1/ha, po wschodach $w$ fazie 3 wąsów czepnych opryskiwanie herbicydem Butoxone M 400 SL (MCPB) w dawce 3,0 1/ha, + Fusilade Forte 150 EC (fluazyfop-P butylu) w dawce 1,5 1/ha.

Doświadczenie polowe założono na glebie zaliczanej do klasy bonitacyjnej IVa i IVb pod względem przydatności rolniczej zaliczanej do kompleksu żytniego bardzo dobrego. Groch uprawiano po pszenżycie jarym. Po zbiorze przedplonu nie wykonywano żadnych zabiegów herbicydowych. Analizę zachwaszczenia poletek wykonano na powierzchni $1 \mathrm{~m}^{2}$ metodą ilościowo-wagową w dwóch terminach, tj. dwa tygodnie po zastosowaniu ostatniego zabiegu herbicydowego i przed zbiorem nasion grochu. Zbioru dokonano $\mathrm{w}$ fazie dojrzałości pełnej nasion. Plon nasion wyliczono na podstawie masy nasion zebranych $\mathrm{z}$ poletka o powierzchni $15 \mathrm{~m}^{2}$ i przedstawiono jako plon w tonach z 1 hektara. Po zważeniu plonu pobrano reprezentatywną próbę nasion do oznaczenia masy 1000 nasion. Wyniki badań opracowano statystycznie za pomocą analizy wariancji, a istotność różnic testowano testem Tukeya przy poziomie istotności $\mathrm{p}=0,05$.

Warunki pogodowe podczas prowadzenia badań były dość zróżnicowane (tab. 1). Według obliczonego współczynnika hydrotermicznego Sielianinowa wszystkie badane sezony wegetacyjne charakteryzowały się brakiem posuchy, jednak na przemian występowały miesiące o skrajnych warunkach, od silnej posuchy po brak posuchy. Najbardziej niekorzystnym sezonem wegetacyjnym był 2009, który w miesiącu kwietniu i lipcu charakteryzował się silną posuchą. Natomiast najkorzystniejszym był 2008, który we wszystkich miesiącach wegetacji charakteryzował się brakiem posuchy.

\section{Wyniki i dyskusja / Results and discussion}

Groch należy do łatwo zachwaszczających się ze względu na długi okres wschodów i wolny początkowy jego rozwój (Borówczak i wsp. 2011).

W przeprowadzonym doświadczeniu dominującymi gatunkami chwastów były: komosa biała (Chenopodium album L.), przytulia czepna (Galium aparine L.), rdest powojowaty (Polygonum convolvulus L.), tasznik pospolity (Capsella bursa pastoris L.), owies głuchy (Avena fatua L.), chwastnica jednostronna (Echinochloa crus-galli L.), perz właściwy (Agropyrum regens L.).

Analizując badane w doświadczeniu czynniki stwierdzono, że sposoby uprawy roli miały istotny wpływ na 
Tabela 1. Charakterystyka warunków pogodowych w latach 2008-2010

Table 1. Characteristic of weather conditions in the years 2008-2010

\begin{tabular}{c|c|c|c|c|c|c|c}
\hline \multirow{2}{*}{ Lata - Years } & \multicolumn{7}{c}{ Miesiące - Months } \\
\cline { 2 - 7 } & & IV & V & VI & VII & VIII & IV-IX \\
\hline \multicolumn{7}{c}{$\begin{array}{c}\text { Współczynnik hydrotermiczny Sielianinowa } \\
\text { Sielianinow's hydrothermal coefficient* }\end{array}$} \\
\hline 2008 & 1,04 & 2,18 & 0,94 & 1,25 & 1,36 & 1,35 \\
2009 & 0,26 & 1,72 & 3,08 & 0,44 & 1,48 & 1,40 \\
2010 & 0,40 & 2,14 & 1,20 & 1,15 & 1,74 & 1,33 \\
\hline
\end{tabular}

*wartość współczynnika (Bac i wsp. 1998) - coefficient value (Bac i wsp. 1998)

$<0,5$ - silna posucha - severe drought

$0,51-0,69$ - posucha - moderate drought

$0,70-0,99$ - słaba posucha - weak drought

$\geq 1$ - brak posuchy - lack of drought

wartość powietrznie suchej masy chwastów oznaczonych w obu terminach badań (tab. 2). Powietrznie sucha masa chwastów oznaczona dwa tygodnie po wykonaniu ostatniego zabiegu była mniejsza na poletkach $\mathrm{z}$ uprawą tradycyjną i wynosiła $46,9 \mathrm{~g} / \mathrm{m}^{2}$, natomiast w przypadku uprawy uproszczonej wynosiła średnio - 59,9 $\mathrm{g} / \mathrm{m}^{2}$. Analizując stan zachwaszczenia przed zbiorem nasion stwierdzono, że powietrznie sucha masa chwastów na obiektach z uprawą tradycyjną była mniejsza o 23,0\% $\mathrm{w}$ porównaniu $\mathrm{z}$ obiektem, na którym wykonano uproszczoną uprawę roli i wynosiła $149,5 \mathrm{~g} / \mathrm{m}^{2}$ (tab. 3). Również Borówczak i wsp. (2011) stwierdzili, że systemy uprawy wpływały istotnie na masę chwastów. Zdaniem Derksena i wsp. (1996) oraz Tørresena i wsp. (2003) przyczyną zwiększenia zachwaszczenia w uprawie uproszczonej i bezorkowej może być mniejsza skuteczność herbicydów, która wynika z większej zawartości substancji organicznej i jej absorbcji substancji aktywnej herbicydu. Odmienne wyniki badań uzyskali Małecka i wsp. (2009), którzy w swoim doświadczeniu obserwowali w łanie grochu siewnego podobną liczbę i masę chwastów w tradycyjnej i uproszczonej uprawie roli, natomiast wprowadzenie siewu bezpośredniego przyczyniło się do zmniejszenia liczby i masy chwastów odpowiednio o 46,5 i $60,4 \%$.

Zachwaszczenie oznaczone w pierwszym i drugim terminie pozwoliło na właściwe porównanie wszystkich sposobów pielęgnacji oraz wykazanie najlepszych wariantów ograniczania powietrznie suchej masy chwastów. Badania własne wykazały, że sposoby pielęgnacji miały istotny wpływ na wartość powietrznie suchej masy chwastów (tab. 2, 3). Najmniejszą powietrznie suchą masę chwastów oznaczoną w pierwszym i drugim terminie, odnotowano na obiekcie, na którym zastosowano mieszaninę herbicydów zwalczających szerokie spektrum chwastów dwu i jednoliściennych (Command 480 EC + Butoxone M 400 + Fusilade Forte 150 EC) i wynosiła ona średnio 13,5 i $56,3 \mathrm{~g} / \mathrm{m}^{2}$. Największą zaś na obiekcie kontrolnym pielęgnowanym wyłącznie mechanicznie odpowiednio 101,6 i $314,5 \mathrm{~g} / \mathrm{m}^{2}$, co znalazło potwierdzenie we wcześniejszych badaniach Gugały i Zarzeckiej (2011). Ponadto wyniki te są zbieżne $\mathrm{z}$ badaniami Księżaka
(2007), którego zdaniem stosowanie mieszaniny trzech herbicydów (Command 480 EC, Barox 460 SL i Targa Super 05 EC) pozwoliło utrzymać plantację wolną od chwastów.

W prowadzonych badaniach własnych wykazano, że zarówno ilość opadów, jak i ich rozkład, decydowały o powietrznie suchej masie chwastów (tab. 2, 3). Największe zachwaszczenie oznaczone w obu terminach obserwacji odnotowano w 2009 roku i wynosiło odpowiednio 63,7 i 193,7 g/m². Również Blecharczyk i wsp. (2010) w swoich badaniach stwierdzili istotne zróżnicowanie w liczbie i masie chwastów w poszczególnych latach badań.

Analiza statystyczna wykazała istotny wpływ metod uprawy roli, sposobów pielęgnacji oraz warunków pogodowych w latach badań na plon nasion grochu siewnego (tab. 4). Większy plon uzyskano na obiekcie $\mathrm{z}$ uprawą tradycyjną średnio o $0,21 \mathrm{t} / \mathrm{ha} \mathrm{w}$ porównaniu $\mathrm{z}$ uprawą uproszczoną.

Faligowska i Szukała (2011) stwierdzili, że systemy uprawy roli modyfikowały plon nasion, jednakże największy uzyskali stosując uprawę bezpłużną, a istotnie mniejszy o $10 \%$ w systemie płużnym.

Uzyskanie wysokiego plonu nasion grochu było możliwe dzięki zastosowaniu chemicznej ochrony przed chwastami, a sposoby pielęgnacji w istotny sposób różnicowały omawianą cechę (tab. 4). Największe plon nasion uzyskano na poletkach, na których zastosowano pielęgnację chemiczną w postaci mieszanin herbicydów, tj. obiekt 5. (Command $480 \mathrm{EC}+$ Butoxone M $400 \mathrm{SL}+$ Fusilade Forte 150 EC) oraz obiekt 4. (Command 480 EC + Butoxone M 400 SL). Plony na tych obiektach wyniosły odpowiednio 3,88 i 3,54 t/ha, zaś najmniejszy plon na obiekcie kontrolnym (pielęgnacja mechaniczna) 2,43 t/ha. Potwierdziły to badania Księżaka (2007), który stosując mieszaninę herbicydów (Command 480 EC, Barox 460 SL i Targa Super 05 EC) uzyskał istotnie większy plon w porównaniu do obiektu pielęgnowanego wyłącznie mechanicznie. Również badania Szwejkowskiej (2006) dowiodły, że najbardziej efektywna dla rozwoju i plonowania grochu była kompleksowa ochrona roślin przeciwko chwastom. 
Tabela 2. Powietrznie sucha masa chwastów po zastosowaniu ostatniego zabiegu $\left[\mathrm{g} / \mathrm{m}^{2}\right]$

Table 2. Air dry weight of weeds after application of the last treatment $\left[\mathrm{g} / \mathrm{m}^{2}\right]$

\begin{tabular}{|c|c|c|c|c|c|c|}
\hline \multirow{2}{*}{$\begin{array}{l}\text { Sposoby pielęgnacji } \\
\text { Weed control methods }\end{array}$} & \multicolumn{2}{|c|}{$\begin{array}{l}\text { Sposoby uprawy roli } \\
\text { Tillage systems }\end{array}$} & \multicolumn{3}{|c|}{$\begin{array}{l}\text { Lata } \\
\text { Years }\end{array}$} & \multirow{2}{*}{$\begin{array}{c}\text { Średnio } \\
\text { Mean }\end{array}$} \\
\hline & $\begin{array}{l}\text { tradycyjna } \\
\text { conventional }\end{array}$ & $\begin{array}{l}\text { uproszczona } \\
\text { reduced }\end{array}$ & 2008 & 2009 & 2010 & \\
\hline $\begin{array}{l}\text { Obiekt kontrolny - Bronowanie } 3 \mathrm{x} \\
\text { Control - Harrowing } 3 \mathrm{x}\end{array}$ & 90,5 & 112,8 & 84,5 & 120,4 & 100,0 & 101,6 \\
\hline Command $480 \mathrm{EC}-0,25$ 1/ha & 50,0 & 60,1 & 47,0 & 67,2 & 51,0 & 55,1 \\
\hline Butoxone M $400 \mathrm{SL}-3,0$ l/ha & 58,7 & 73,1 & 58,9 & 77,3 & 61,5 & 65,9 \\
\hline $\begin{array}{l}\text { Command } 480 \mathrm{EC}-0,25 \text { 1/ha }+ \\
\text { Butoxone M } 400 \mathrm{SL}-3,0 \text { 1/ha }\end{array}$ & 25,1 & 36,6 & 25,4 & 36,9 & 30,1 & 30,8 \\
\hline $\begin{array}{l}\text { Command } 480 \text { EC }-0,25 \text { 1/ha + Butoxone M } 400 \\
\text { SL }-3,0 \text { 1/ha + Fusilade Forte } 150 \text { EC }-1,5 \text { 1/ha }\end{array}$ & 10,2 & 16,8 & 10,3 & 16,9 & 13,3 & 13,5 \\
\hline Średnio - Mean & 46,9 & 59,9 & 45,2 & 63,7 & 51,2 & - \\
\hline
\end{tabular}

Tabela 3. Powietrznie sucha masa chwastów przed zbiorem grochu $\left[\mathrm{g} / \mathrm{m}^{2}\right]$

Table 3. Air dry weight of weeds before pea harvest $\left[\mathrm{g} / \mathrm{m}^{2}\right]$

\begin{tabular}{|c|c|c|c|c|c|c|}
\hline \multirow{2}{*}{$\begin{array}{c}\text { Sposoby pielęgnacji } \\
\text { Weed control methods }\end{array}$} & \multicolumn{2}{|c|}{$\begin{array}{l}\text { Sposoby uprawy roli } \\
\text { Tillage systems }\end{array}$} & \multicolumn{3}{|c|}{$\begin{array}{l}\text { Lata } \\
\text { Years }\end{array}$} & \multirow{2}{*}{$\begin{array}{l}\text { Średnio } \\
\text { Mean }\end{array}$} \\
\hline & $\begin{array}{l}\text { tradycyjna } \\
\text { conventional }\end{array}$ & $\begin{array}{l}\text { uproszczona } \\
\text { reduced }\end{array}$ & 2008 & 2009 & 2010 & \\
\hline $\begin{array}{l}\text { Obiekt kontrolny - Bronowanie } 3 \mathrm{x} \\
\text { Control - Harrowing } 3 \mathrm{x}\end{array}$ & 272,5 & 356,5 & 270,9 & 352,4 & 320,2 & 314,5 \\
\hline Command $480 \mathrm{EC}-0,25$ 1/ha & 160,3 & 216,3 & 159,5 & 216,0 & 189,4 & 188,3 \\
\hline Butoxone M $400 \mathrm{SL}-3,0 \mathrm{l} / \mathrm{ha}$ & 172,9 & 224,9 & 170,4 & 225,2 & 201,3 & 198,9 \\
\hline $\begin{array}{l}\text { Command } 480 \mathrm{EC}-0,25 \mathrm{l} / \mathrm{ha}+ \\
\text { Butoxone M } 400 \mathrm{SL}-3,0 \mathrm{l} / \mathrm{ha}\end{array}$ & 92,5 & 110,2 & 93,5 & 109,5 & 101,3 & 101,4 \\
\hline $\begin{array}{l}\text { Command } 480 \text { EC }-0,25 \text { 1/ha + Butoxone M } 400 \\
\text { SL }-3,0 \text { 1/ha + Fusilade Forte } 150 \text { EC }-1,5 \text { 1/ha }\end{array}$ & 49,3 & 63,2 & 48,1 & 65,2 & 55,7 & 56,3 \\
\hline Średnio - Mean & 149,5 & 194,2 & 148,5 & 193,7 & 173,6 & - \\
\hline
\end{tabular}

NIR $(0,05)$ dla - LSD (0.05) for: lat - years - 6,4; sposobów uprawy roli - tillage systems - 5,1; sposobów pielęgnacji - weed control methods $-10,5$

Tabela 4. Plon nasion grochu siewnego [t/ha]

Table 4. Seed yield of pea [t/ha]

\begin{tabular}{|c|c|c|c|c|c|c|}
\hline \multirow{2}{*}{$\begin{array}{l}\text { Sposoby pielęgnacji } \\
\text { Weed control methods }\end{array}$} & \multicolumn{2}{|c|}{$\begin{array}{l}\text { Sposoby uprawy roli } \\
\text { Tillage systems }\end{array}$} & \multicolumn{3}{|c|}{$\begin{array}{l}\text { Lata } \\
\text { Years }\end{array}$} & \multirow{2}{*}{$\begin{array}{l}\text { Średnio } \\
\text { Mean }\end{array}$} \\
\hline & $\begin{array}{l}\text { tradycyjna } \\
\text { conventional }\end{array}$ & $\begin{array}{l}\text { uproszczona } \\
\text { reduced }\end{array}$ & 2008 & 2009 & 2010 & \\
\hline $\begin{array}{l}\text { Obiekt kontrolny - Bronowanie } 3 \mathrm{x} \\
\text { Control - Harrowing } 3 \mathrm{x}\end{array}$ & 2,54 & 2,32 & 2,55 & 2,45 & 2,30 & 2,43 \\
\hline Command 480 EC - 0,25 1/ha & 3,12 & 2,97 & 3,20 & 2,94 & 2,99 & 3,04 \\
\hline Butoxone M $400 \mathrm{SL}-3,0$ l/ha & 3,00 & 2,81 & 3,05 & 2,75 & 2,91 & 2,90 \\
\hline $\begin{array}{l}\text { Command } 480 \mathrm{EC}-0,25 \mathrm{l} / \mathrm{ha}+ \\
\text { Butoxone M } 400 \mathrm{SL}-3,0 \mathrm{l} / \mathrm{ha}\end{array}$ & 3,69 & 3,45 & 3,72 & 3,40 & 3,50 & 3,54 \\
\hline $\begin{array}{l}\text { Command } 480 \mathrm{EC}-0,25 \mathrm{l} / \mathrm{ha}+\text { Butoxone M } \\
400 \mathrm{SL}-3,0 \mathrm{l} / \mathrm{ha}+\text { Fusilade Forte } 150 \mathrm{EC}- \\
1,5 \mathrm{l} / \mathrm{ha}\end{array}$ & 4,01 & 3,75 & 4,10 & 3,71 & 3,85 & 3,88 \\
\hline Średnio - Mean & 3,27 & 3,06 & 3,32 & 3,05 & 3,11 & - \\
\hline
\end{tabular}

NIR $(0,05)$ dla - LSD (0.05) for: lat - years - 0,14; sposobów uprawy roli - tillage systems - 0,12; sposobów pielęgnacji - weed control methods $-0,65$ 
Tabela 5. Masa tysiąca nasion $[\mathrm{g}]$

Table 5. Weight of 1000 seeds [g]

\begin{tabular}{|c|c|c|c|c|c|c|}
\hline \multirow{2}{*}{$\begin{array}{c}\text { Sposoby pielęgnacji } \\
\text { Weed control methods }\end{array}$} & \multicolumn{2}{|c|}{$\begin{array}{l}\text { Sposoby uprawy roli } \\
\text { Tillage systems }\end{array}$} & \multicolumn{3}{|c|}{$\begin{array}{l}\text { Lata } \\
\text { Years }\end{array}$} & \multirow{2}{*}{$\begin{array}{l}\text { Średnio } \\
\text { Mean }\end{array}$} \\
\hline & $\begin{array}{l}\text { tradycyjna } \\
\text { conventional }\end{array}$ & $\begin{array}{l}\text { uproszczona } \\
\text { reduced }\end{array}$ & 2008 & 2009 & 2010 & \\
\hline $\begin{array}{l}\text { Obiekt kontrolny - Bronowanie } 3 \mathrm{x} \\
\text { Control - Harrowing } 3 \mathrm{x}\end{array}$ & 253,1 & 247,9 & 255,3 & 246,1 & 252,0 & 251,1 \\
\hline Command $480 \mathrm{EC}-0,25$ 1/ha & 257,0 & 249,9 & 258,0 & 248,9 & 253,7 & 253,5 \\
\hline Butoxone M $400 \mathrm{SL}-3,0 \mathrm{l} / \mathrm{ha}$ & 255,2 & 248,8 & 256,0 & 247,0 & 253,0 & 252,0 \\
\hline $\begin{array}{l}\text { Command } 480 \mathrm{EC}-0,25 \mathrm{l} / \mathrm{ha}+ \\
\text { Butoxone M } 400 \mathrm{SL}-3,0 \mathrm{l} / \mathrm{ha}\end{array}$ & 258,3 & 251,1 & 259,4 & 250,5 & 254,1 & 254,7 \\
\hline $\begin{array}{l}\text { Command } 480 \text { EC }-0,25 \text { 1/ha + Butoxone M } 400 \\
\text { SL }-3,0 \text { l/ha + Fusilade Forte } 150 \text { EC }-1,5 \text { 1/ha }\end{array}$ & 260,0 & 254,9 & 261,0 & 253,4 & 258,1 & 257,5 \\
\hline Średnio - Mean & 256,7 & 250,2 & 257,9 & 249,2 & 254,2 & - \\
\hline
\end{tabular}

NIR $(0,05)$ dla - LSD $(0.05)$ for: lat - years - 2,7; sposobów uprawy roli - tillage systems - 2,01; sposobów pielęgnacji - weed control methods $-3,2$

Z badań Alvino i Leone (1993), Fougereux i wsp. (1997), Grabowskiej i wsp. (2005), Grabowskiej i Banaszkiewicz (2009) oraz Florek i wsp. (2012) wynika, że zasadniczy wpływ na wielkość plonów grochu siewnego ma przebieg warunków pogodowych panujący w latach badań.

W badaniach własnych największy średni plon 3,32 t/ha uzyskano w 2008 roku, charakteryzującym się równomiernym rozkładem opadów. Najmniejszy plon średnio 3,05 t/ha zebrano w 2009 roku, o największych opadach i nierównomiernym ich rozkładzie.

Analiza statystyczna potwierdziła, że na masę tysiąca nasion miały wpływ sposoby uprawy roli, sposoby pielęgnacji i warunki pogodowe w poszczególnych sezonach wegetacyjnych (tab. 5). Istotnie większą masą odznaczały się nasiona zebrane z obiektów, na których zastosowano tradycyjną uprawę roli - średnio $256,7 \mathrm{~g}$. W badaniach Faligowskiej i Szukały (2011) systemy uprawy roli nie miały wpływu na masę 1000 nasion.

$\mathrm{Z}$ badań własnych wynika również, że na wielkość omawianej cechy miały istotny wpływ sposoby pielęgnacji chemicznej. Największą masę tysiąca nasion uzyskano, na obiektach, gdzie stosowano mieszaninę herbicydów Com- mand $480 \mathrm{EC}+$ Butoxone M $400 \mathrm{SL}+$ Fusilade Forte 150 EC. Średnia MTN na tym obiekcie wyniosła 257,5 g. Sekutowski i Badowski (2011) wykazali nieznaczny wpływ substancji czynnej herbicydów na kształtowanie się MTN. Groch jest gatunkiem, który wyraźnie reaguje na ilość i rozkład opadów. Z przeprowadzonych badań wynika, że masa tysiąca nasion istotnie była różnicowana w poszczególnych latach badań. Najwyższą wartość omawianej cechy uzyskano w 2008 roku (257,9 g), zaś najmniejszą w 2009 (249,2 g).

\section{Wnioski / Conclusions}

1. Użyte $w$ doświadczeniu herbicydy i ich mieszaniny wpłynęły korzystnie na ograniczenie zachwaszczenia, w porównaniu do kontroli z pielęgnacją mechaniczną jednocześnie powodując wzrost plonu i masy tysiąca nasion grochu siewnego.

2. Zmienne warunki pogodowe w poszczególnych sezonach wegetacyjnych wpływały istotnie na ograniczenie powietrznie suchej masy chwastów, a tym samym na wielkość plonu nasion grochu.

\section{Literatura / References}

Alvino A., Leone A. 1993. Response to low soil water potential in pea genotypes (Pisum sativum L.) with different leaf morphology. Scientia Hortic. 53: 21-34.

Bac S., Koźmiński Cz., Rojek M. 1998. Agrometeorologia. Wyd. PWN, Warszawa, 274 ss.

Blecharczyk A., Małecka I., Sawinska Z. 2010. Zachwaszczenie grochu w siewie bezpośrednim. [Weed infestation of field pea in direct drilling]. Prog. Plant Prot./Post. Ochr. Roślin 50 (2): 775-778.

Borówczak F., Rębarz K., Grześ S., Maciejewski T. 2011. Wpływ deszczowania i systemu uprawy roślin na zachwaszczenie grochu siewnego w trzeciej rotacji czteropolowego płodozmianu. [Effect of irrigation and cultivation system on weed infestation of pea in the third four-field crop rotation]. Prog. Plant Prot./Post. Ochr. Roślin 51 (2): 842-846.

Derksen D.A., Blackshaw R.E., Boyetchko S.M. 1996. Sustainability, conservation tillage and weeds in Canada. Can. J. Plant Sci. 76 (4): 651-659.

Faligowska A., Szukała J. 2011. Wpływ deszczowania, systemów uprawy roli i polimeru na plonowanie i wartość siewną nasion grochu. Fragm. Agron. 28 (1): 15-22. 
Florek J., Czerwińska-Kayzer D., Jerzak M.A. 2012. Aktualny stan i wykorzystanie produkcji upraw roślin strączkowych. Fragm. Agron. 29 (4): 45-55.

Fougereux J.A., Doré T., Ladonne F., Fleury A. 1997. Water stress during reproductive stages affects seed quality and yield of pea (Pisum sativum L.). Crop. Sci. 37: 1247-1252.

Grabowska K., Banaszkiewicz B. 2009. Wpływ temperatur powietrza i opadów atmosferycznych na plonowanie grochu siewnego w środkowej Polsce. Acta Agrophys. 13 (1): 113-120.

Grabowska K., Banaszkiewicz B., Grabowski J. 2005. Zależność plonowania grochu siewnego od czynników meteorologicznych w północno-wschodniej Polsce. Inż. Ekol. 12: 270-271.

Gugała M., Zarzecka K. 2011. Regulacja zachwaszczenia w uprawie grochu siewnego odmiany Wiato. [Regulation of weed infestation in pea crop, cultivar Wiato]. Prog. Plant Prot./Post. Ochr. Roślin 51 (1): 342-347.

Księżak J. 2007. Wpływ wybranych herbicydów na rozwój i plonowanie wąskolistnej odmiany grochu siewnego. [Influence of selected herbicides on development and yielding of semileafless variety of pea]. Prog. Plant Prot./Post. Ochr. Roślin 47 (3): $169-172$.

Małecka I., Blecharczyk A., Dobrzeniecki T. 2009. Produkcyjne i środowiskowe skutki wieloletniego stosowania systemów bezorkowych w uprawie grochu siewnego. Fragm. Agron. 26 (3): 118-121.

Sekutowski T., Badowski M. 2011. Wpływ zachwaszczenia oraz ochrony herbicydowej na plonowanie grochu siewnego (Pisum sativum L.). [Effect of weed infestation and herbicide protection on yielding of pea (Pisum sativum L.)]. Prog. Plant Prot./Post. Ochr. Roślin 51 (4): 1858-1863.

Szwejkowska B. 2006. Reakcja odmian grochu siewnego (Pisum sativum L.) na różne metody zwalczania chwastów. Acta Sci. Pol., Agricultura 5 (1): 71-82.

Tørresen K.S., Skuterud R., Tandsaether H.J., Hagemo M.B. 2003. Long-term experiments with reduced tillage in spring cereals. I. Effects on weed flora, weed seedbank and grain yield. Crop Prot. 22: 185-200. 